\title{
Research on Virtual Teaching Interacting with Practice on the Biomedical Electronics Experiment
}

\author{
Min $\operatorname{Lin}^{1,2}$ \\ 1. School of Medical Instrument \\ Shanghai University of Medicine and Health Sciences \\ 2. Shanghai Guanghua Hospital \\ Shanghai, China \\ linm@ sumhs.edu.cn
}

\author{
Chun-yu Shan \\ School of Medical Instrument \\ Shanghai University of Medicine and Health Sciences \\ Shanghai, China \\ shancy@sumhs.edu.cn
}

\begin{abstract}
The comprehensive, designing and creative experiments can facilitate students' creative thinking and develop their practical operation. This paper introduces the application of the experimental mode of the virtual simulation interacting with the practice in the comprehensive, designing and creative experiments. Based on the explanation of the idea of the virtual simulation interacting with the practical experiment, it takes the example of the Biomedical Electronics experiment to elaborate in detail the implementation of this experimental mode including the schedule arrangement, the process management and the result evaluation.
\end{abstract}

Keywords—virtual simulation interacting with the practice; comprehensive experiment; creative experiment; Biomedical Electronics

\section{INTRODUCTION}

Experimental teaching plays an important role in developing students' engineering knowledge and improving their creative ability. It is one of the key points for modern higher education to explore the experimental teaching modes which can improve students' ability of analyzing and solving problems [1,2]. The comprehensive, designing and creative practices should have a higher percentage in electronic experiments.

\section{RELATED WORK}

In the recent 30 years, the virtual simulation technology has been applied in the electronic related experiments to motivate students [3]. They design and analyze the electronic circuits in the virtual platform and then they build the hardware circuit by using the actual electronic components. This experimental mode provides a vividly graphic interface to make students better understand the principles of the designed circuits. So it has been more and more popular applied in the compressive and creative experiments.

For example, the Department of Biomedical Engineering in University of California, Irvine in USA carries out the Biomedical Electronics experiment on the NI Elvis II virtual platform (http://engineering.uci.edu/dept/bme). Students must complete the theoretical analysis and computation before they enter the lab. Based on the theoretical analysis result, students start the simulation on the virtual platform and then build the actual circuit on the hardware board connected with the computer. By measuring circuit parameters in real time, they can verify the theoretical analysis results. Although these experiments are implemented on the virtual platform, the experimental tasks only involve the parameters detecting or simple analysis on electronic modules. Their aim is to verify some important theoretical points which are similar as the traditional experiments which are carried out by connecting electronic modules fixed in the experimental box with wires. Therefore, these tasks are not the comprehensive and designing experiments.

Take another example of experiments for Principles and Practices of Biomedical Engineering implemented by virtual interaction with the reality in National Central University in Taiwan. This experiment is composed of ten tasks which focus on measurement and analysis on medical physiology such as measurements of blood, temperature, Electrocardiograph and so on. While these tasks are not related to the electronic components and their applications ( http://sine.ni.com/cs/app/doc/P/id/cs16365\#prettyPhoto).

In this paper, we integrate the separate knowledge points from a series of electrical-related courses such as Basic Electrical Circuits, Analog Electrical Circuits, Digital Electrical Circuits and Biomedical Electronics to design the comprehensive and creative experiment through the virtual platform interacting with the practical operation. The aim of such experiment is not only to facilitate students' primary experience of designing and developing biomedical electronic system but also to promote their abilities of analyzing and solving problems and develop their creative thinking and scientific literacy $[4,5]$. In addition, we can train the teaching stuff with high creative spirit to ensure the qualification of experimental teaching, thereby forming a good circulation and gathering strength for all kinds of high-level competitions. 


\section{IDEA OF THE VIRTUAL SIMULATION INTERACTING WITH THE PRACTICAL EXPERIMENT}

In this paper, the idea of the virtual simulation interacting with the practical experiment includes two meanings: 1) the virtual software interacting with the actual hardware; 2) the teacher equally communicating and interacting with students during the whole experiment. These two aspects are both essential to successfully complete the comprehensive and creative experiments.

The idea is implemented by the following three stages (Fig.1). In every stage, students are divided into several groups and there are two students in each group.

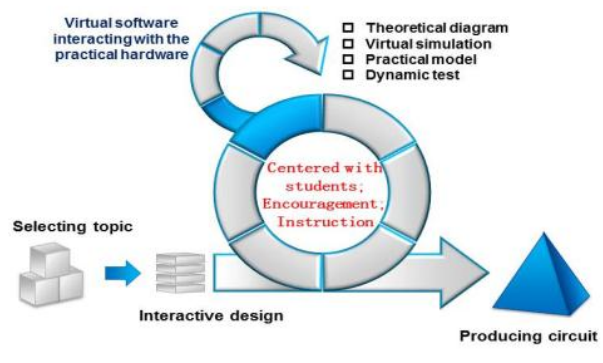

Fig.1. Diagram of experimental idea

1. Selecting topic. The teacher should be responsible for providing a few of designing topics and then guide students to select a suitable topic according to their own interests combining with their study grades.

2. Interactive design. This stage is a dynamically circulation process which includes four steps.

1) Students are encouraged to explore independently and discuss all possibly theoretical design schemes in groups.

2) Then students are required to virtually simulate these theoretical schemes to observe their feasibility.

3) According to the simulation result, students build the circuit model with electrical hardware components on the Elvis II board from National Instruments. The hardware board connects with the computer which is installed the virtual simulation software.

4) The circuit model is tested by virtual simulation interacting with the practical board. According to the difference between the test results and the design requirements, students should dynamically revise the parameters in the scheme in time to get the best performance of the circuit model.

Then, it circulates from step 2 to step 4.

3. Producing circuit. Students make the real hardware circuit by welding the electrical components on the hardware board according to the circuit model with the best performance.

During this process, the smooth interactions between students and the teacher, between students and experimental resources, between the teacher and experimental resources, and between students are important to get the successful experimental results [6, 7]. The whole experiment should be implemented centered with students while the teacher plays a role in guiding, helping and facilitating students' study. Before the beginning of the experiment, the teacher should guide students to select the suitable topic and then check their preview work. During the experiment, the teacher should create the friendly and democratic atmosphere and help students to get information that they need to solve problems. Furthermore, the teacher should estate experimental results in each operation stage and give feedback to students in time to facilitate their adjustment.

\section{EXAMPLE OF THE VIRTUAL SimUlation INTERACTING WITH THE PRACTICAL EXPERIMENT}

We take the example of the Biomedical Electronics course to introduce the arrangement and implementation of the virtual simulation interacting with the practical experiment. In order to develop students' teamwork awareness, they are divided into several groups and each group has two students.

The Biomedical Electronics course mainly focuses on:

a) Analysis and computation on the basic circuits which are composed of the separated components such as resistors, capacitors, inductors, diodes and transistors.

b) Analysis and design on the classical integrated analog circuits such as proportional amplifiers, additive operation amplifiers, differential amplifiers, power amplifiers, comparators and active filters. 
c) Analysis and design on the combinational logic circuits and sequential logic circuits.

d) Analysis and computation on the general medical electronical systems.

Based on above knowledge points, we provide six selective topics as the following to students.

1) Temperature measurement and control system of neonatal incubator;

2) Design of amplifier and filter of bioelectrical signal (ECG, EEG, EOG);

3) Design of simple detector of pulse;

4) Design of prioritized call system for the hospital ward;

5) Laparoscope insulation defect inspection circuit;

6) Design of simple electrical stimulator.

Besides, students are allowed to decide their own topics in terms of their interesting based on sufficient discussion with the teacher.

The Biomedical Electronics experiment is scheduled for 2 weeks (Table 1).

Table 1. Schedule of the experiment for two weeks

\begin{tabular}{|c|c|c|c|c|}
\hline No. & Day & Task & Ability & Result \\
\hline \multirow[b]{2}{*}{$\begin{array}{c}\text { Week } \\
1\end{array}$} & $\begin{array}{l}\text { Monday } \\
\text { Wednesday }\end{array}$ & design scheme & $\begin{array}{l}\text { 1. information search } \\
\text { 2. knowledge integration } \\
\text { 3. circuit analysis }\end{array}$ & $\begin{array}{l}\text { (1) circuit draft } \\
\text { (2) preview report }\end{array}$ \\
\hline & Thursday $\sim$ Friday & $\begin{array}{l}\text { virtual simulation } \\
\text { interaction with the } \\
\text { circuit model }\end{array}$ & $\begin{array}{l}\text { 1. simulation operation } \\
\text { 2. modeling circuit } \\
\text { 3. transfer from } \\
\text { simulation to the circuit } \\
\text { model }\end{array}$ & $\begin{array}{l}\text { (1) simulation result } \\
\text { (2) circuit model }\end{array}$ \\
\hline \multirow{3}{*}{$\begin{array}{c}\text { Week } \\
2\end{array}$} & $\begin{array}{l}\text { Monday } \\
\text { Wednesday }\end{array}$ & $\begin{array}{l}\text { make the hardware } \\
\text { circuit }\end{array}$ & $\begin{array}{l}\text { 1. PCB layout } \\
\text { 2. components welding } \\
\text { 3. circuit test }\end{array}$ & $\begin{array}{c}\text { hardware circuit } \\
\text { board }\end{array}$ \\
\hline & Thursday & $\begin{array}{l}\text { write experimental } \\
\text { report }\end{array}$ & $\begin{array}{l}\text { 1. summarizing and } \\
\text { analyzing } \\
\text { 2. report writing }\end{array}$ & experimental report \\
\hline & Friday & oral presentation & $\begin{array}{l}\text { 1. PPT making } \\
\text { 2. oral expression }\end{array}$ & PPT \\
\hline
\end{tabular}

In the first week, from Monday to Wednesday, students should look up materials to try their best to get information which is helpful to their design. Based on this information, they have to draw the circuit draft and complete the preview report. The teacher should check students' draft to make sure its feasibility.

On Thursday and Friday of the first week, each group should adopt Multisim software to simulate and analyze their design scheme, and then construct the circuit model with the hardware components on the Elvis II+ board. The running results of the circuit can be displayed in time in the virtual platform installed in PC. Therefore, students can dynamically adjust the parameters of the circuit model until they achieve the best performance of the circuit model (Fig.2).

In the second week, from Monday to Wednesday, each group is required to complete the PCB layout and weld the hardware components. Then, they should test the performance by measuring the parameters of the circuit until the circuit meets the preset requirements (Fig.2).

On Thursday and Friday of the second week, each group is required to write an experimental report including introduction of the whole experimental process, processing of experimental data, and analysis of experimental results. Based on the report, each group should make PPT slides to take part in the oral presentation in the class.

During the experimental process, students should try their best to think and solve problems independently while the teacher just leads the way to solutions instead of answering questions directly. Students but not the teacher is the main part of the experiment. The smooth communication between the teacher and students is very important. Therefore, the score is evaluated comprehensively including the preview report, the experimental operation, data processing, experimental report and oral presentation (Table 2). 
Table 2. Evaluation of the experiment

\begin{tabular}{|c|c|c|c|c|c|}
\hline No. & Criteria & $\begin{array}{c}\text { Self-evaluation } \\
(20 \%)\end{array}$ & $\begin{array}{c}\text { Peer evaluation between } \\
\text { groups (30\%) }\end{array}$ & $\begin{array}{c}\text { Evaluation by the } \\
\text { teacher }(50 \%)\end{array}$ & Score \\
\hline 1 & Design scheme (25\%) & & & & \\
\hline 2 & Simulation result (20\%) & & & & \\
\hline 3 & Circuit test (30\%) & & & & \\
\hline 4 & Experimental report (15\%) & & & & \\
\hline 5 & Oral presentation $(10 \%)$ & & & & \\
\hline
\end{tabular}

V. SUMMARY

In Shanghai University of Medicine and Health Sciences, over 100 students majoring in Biomedical Engineering have the Biomedical Electronics experiment every year. In order to develop students abilities of creative thinking and practical application, we researched on virtual teaching interacting with the practice for this comprehensive and designing experiment. The successful implemention of the experiment as well as its good feedback give us confidence to spread the idea of virtual teaching interacting with the practice to other experimental courses.

\section{ACKNOWLEDGMENT}

This research was financially supported by the Shanghai University of Medicine and Health Sciences (JG-(17)-04-B1-01).

\section{REFERENCES}

[1] Y.L. Yan, W.X. Han, J. Yan, H.Y. Han, "Exploration on comprehensive and designing experimental teaching reform of electronic technology," Laboratory Science, vol.18, No.1, pp.97-99, 2015.

[2] Z.B. Li, G.Z, Y.F. Yao, J.D, Zhao, "Reform and practice of experimental teaching for fundamental electronic comprehensive/design experiments," Laboratory Science, vol.18, No.6, pp.109-111, 2015.

[3] Y.P. Zhou, C.T. Mei, H. Xu, "An electronics technology teaching and experiment platform based on virtual instrument technique," Experimental Technology and Management, vol.23, No.3, pp.73-75, 2006.

[4] Y. Wang, "Discussion on the teaching method of the comprehensive and designing experiments in electronic circuits," Journal of EEE, vol.25, No.3, pp.9597, 2003.

[5] Z.G. Nie, Z.D. Liu, "Synthesis and designing experiments in experimental teaching," Experimental Technology and Management, vol.25, No.3, pp.140-141, 2008.

[6] Y.S. Tian, W.H. Liu, J.C, "Wang, Exploration and practice on construction of comprehensive and designing experimental projects," Experimental Technology and Management, vol.29, No.2, pp.126-129, 2012.

[7] X.K. Wu, C.Z. Zhu, Y.C. Zhong, "Synthesizing principles of comprehensive experiments," Research and Exploration in Laboratory, vol.26, No.6, pp.8991, 2007. 